\title{
JOURNAL.RU
}

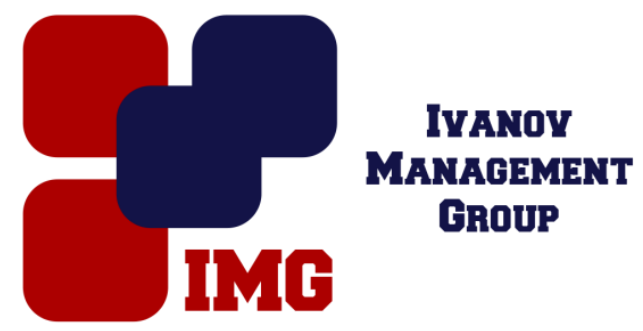

Николаев А.Г.

Москва, Россия

doi: 10.18411/1j-31-05-2017-51

idsp 000001:1j-31-05-2017-51

\section{Субъекты органов внутренних дел и решаемые ими задачи в сфере охраны собственности}

\section{Аннотация}

Данная научная статья посвящена построению государственной системы охраны собственности, определяет место и роль функциональных подразделений полиции МВД России, участвующих в охране общественного порядка в рассматриваемой сфере административно-правовых отношений.

Ключевые слова: охрана, собственность, государственная система охраны собственности, административно-правовая охрана собственности, подразделения полиции, участвующие в охране общественного порядка, подразделения участковых уполномоченных полиции, подразделения патрульно-постовой службы, подразделения по обеспечению безопасности дорожного движения, подразделения по исполнению административного законодательства, подразделения по делам несовершеннолетних, подразделения по делам несовершеннолетних.

Реализация права защиты имущества государственными органами основана на формировании концептуальных задач и способов реализации государственной политики в сфере имущественной безопасности и осуществлении комплекса взаимосвязанных мер правового, социального и технического характера. В связи с этим обеспечение имущественной безопасности с помощью государственных структур является одним из основных направлений деятельности правоохранительных органов государства. 
Должностные лица органов внутренних дел отдельных подразделений, участвующих в охране общественного порядка, наделены соответствующими их административно-правовому статусу правами и обязанностями по профилактике, выявлению и пресечению административных правонарушений в области охраны собственности [Ошибка! Источник ссылки не найден., 112c.].

Подразделения участковых уполномоченных полиции играют важную роль в профилактике преступлений и иных правонарушений в области сохранности собственности, а также охране общественного порядка и обеспечении общественной безопасности [Ошибка! Источник ссылки не найден.].

При несении службы участковый уполномоченный полиции (далее УУП) в данном направлении:

$\checkmark$ предупреждает и пресекает преступления и административные правонарушения в области охраны собственности;

$\checkmark$ выявляет и раскрывает преступления;

$\checkmark$ осуществляет производство по делам об административных правонарушениях в области охраны собственности [Ошибка! Источник ссылки не найден., 192с.];

$\checkmark$ принимает участие в государственном федеральном контроле в области оборота оружия (к примеру, законность владения, условия хранения и сохранности оружия).

Свою служебную деятельность УУП осуществляет на административном участке, который приказом начальника территориального органа МВД России на районном уровне закрепляется: в городах - исходя из численности проживающего населения и граждан, состоящих на профилактическом учете, в сельской местности - в границах одного или нескольких объединенных общей территорией сельских населенных пунктов, на территории закрытого административно-территориального образования - в границах контролируемой зоны, в соответствии с установленными нормативами их штатной численности (ст.10 Приказа МВД России №1166-2012г.).

Участковый уполномоченный полиции при несении службы на административном участке обязан:

$\checkmark$ принимать заявления, сообщения и иную информацию о преступлениях, административных правонарушениях и происшествиях, незамедлительно передавать полученную информацию оперативному дежурному с использованием всех 
доступных средств связи, при прибытии на участковый пункт полиции либо в иное служебное помещение записывать полученную информацию в журнал учета приема граждан, их обращений и заявлений (ст.37.1. Приказа МВД России №1166-2012г.).

$\checkmark$ принимать при чрезвычайных ситуациях неотложные меры по спасению граждан, охране имущества, оставшегося без присмотра, содействовать в этих условиях бесперебойной работе спасательных служб; обеспечивать общественный порядок при проведении карантинных мероприятий во время эпидемий и эпизоотий (ст.37.10. Приказа МВД России №1166-2012г.).

$\checkmark$ изымать у граждан и должностных лиц документы, имеющие признаки подделки, а также вещи, изъятые из гражданского оборота или ограниченно оборотоспособные, находящиеся у них без специального разрешения, а также при наличии иных оснований, предусмотренных законодательством Российской Федерации, с составлением протокола и вручением его копии указанным гражданам и должностным лицам (ст.37.18. Приказа МВД России №1166-2012г.).

Действия участкового уполномоченного полиции при проведении профилактического обхода административного участка:

- профилактический обход административного участка включает в себя посещение зданий, строений и сооружений, расположенных на административном участке (при необходимости обследуются подъезды, чердачные и подвальные помещения жилых домов, пустующих и подлежащих сносу строений); посещение лиц, состоящих на профилактических учетах в органах внутренних дел; ознакомление с жильцами квартир (жилых домов, комнат) с соблюдением требований ст.15 Ф3 «О полиции», встречи для решения вопросов взаимодействия с собственниками или представителями собственников объектов, расположенных на административном участке (ст.41. Приказа МВД России №11662012г.).

- при проведении профилактического обхода участковый уполномоченный полиции обязан разъяснять гражданам о мерах предосторожности в целях предупреждения преступлений и административных правонарушений, направленных на обеспечение 
их личной и имущественной безопасности (в том числе: установке дверных замков, смотровых глазков, камер видеонаблюдения, видеодомофонов и других технических средств защиты; постановке квартир под охрану подразделений вневедомственной охраны войск национальной гвардии Российской Федерации, иных охранных организаций; информировании дежурной части территориального органа МВД России на районном уровне или непосредственно участкового уполномоченного полиции о появлении на административном участке подозрительных лиц, брошенного, бесхозяйного автомототранспорта или иных предметов) (ст.45. Приказа МВД России №1166-2012г.).

При ознакомлении с объектами, расположенными на административном участке, участковый уполномоченный полиции обязан:

- обращать внимание на техническую укрепленность окон, дверей, запасных входов (выходов), смежных стен объектов с подъездами, квартирами, жилыми домами, а также на то, сдаются ли данные объекты под охрану (сигнализацию) (ст.48.1. Приказа МВД России №1166-2012г.);

- устанавливать вид охраны объектов, наличие у сотрудников охраны оружия, необходимых разрешительных документов на осуществление охранной деятельности (ст.48.2. Приказа МВД России №1166-2012г.);

- проводить разъяснительную работу с сотрудниками охраны и гражданами, работающими на объектах, о принятии мер по сохранности имущества (в том числе о целесообразности установки охранной сигнализации), о действиях в чрезвычайной ситуации, при угрозе совершения террористического акта (ст.48.3. Приказа МВД России №1166-2012г.).

Результаты ознакомления с объектами заносятся в паспорт на административный участок. При получении в результате профилактического обхода информации о лицах, которые могут быть причастны к совершению преступлений и административных правонарушений, участковый уполномоченный полиции докладывает рапортом на имя начальника территориального органа МВД России на районном уровне.

Также УУП принимает участие в мероприятиях по контролю за обеспечением условий хранения (сохранностью) гражданского, служебного, 
боевого и наградного оружия, боеприпасов, патронов к оружию, находящихся в собственности или во временном пользовании граждан. При выявлении правонарушений в области оборота оружия в пределах компетенции принимает меры по привлечению лица к предусмотренной законодательством ответственности, изъятию оружия и патронов к нему и докладывает рапортом на имя начальника территориального органа МВД России (ст.80.2.1. Приказа МВД России №1166-2012г.).

Существуют определенные особенности несения службы участковым уполномоченным полиции в сельском поселении по сохранности имущества собственников, к примеру, УУП при несении службы в сельском поселении должен:

$\checkmark$ знать в пределах своего административного участка местонахождение селений, хуторов, усадеб, фельдшерскоакушерских пунктов, ветеринарных пунктов, станций, скотопрогоночных дорог, ферм, а также направление и состояние рек, шоссейных, грунтовых и железных дорог, горных троп, лесов, степень их проходимости, местонахождение и состояние гатей, мостов, переправ, бродов, а также местонахождение болот и степень их проходимости (ст.82.1. Приказа МВД России №1166-2012г.);

$\checkmark$ посещать ежемесячно наиболее крупные населенные пункты, рынки, станции, пристани, аэродромы и другие общественные места с массовым пребыванием граждан, а также осматривать малопосещаемые места, заброшенные строения и территории (ст.82.2. Приказа МВД России №1166-2012г.).

Подразделения патрульно-постовой службы осуществляют предупреждение и пресечение преступлений и административных правонарушений имущественного характера на постах и маршрутах патрулирования [Ошибка! Источник ссылки не найден.]. При реализации своих функций, данные подразделения пресекают противоправные деяния и задерживают лиц, совершивших преступления, по «горячим следам».

Сотрудники подразделений ППСП, заступающие на службу, в целях выявления и предупреждения правонарушений против собственности должны знать (ст. 65 Устава ППСП):

$\checkmark$ приметы лиц, транспортных средств и иного имущества, объявленных в розыск; 
$\checkmark$ месторасположение в районе поста (маршрута) особо важных объектов и объектов жизнеобеспечения, органов государственной власти, правоохранительных органов, подразделений пожарной охраны, общежитий, предприятий, организаций и учреждений, спортивных и культурно-зрелищных объектов, предприятий общественного питания, торговли, здравоохранения и режим их работы, остановок общественного транспорта.

Во время службы наряды должны обращать особое внимание на (ст. 72 Устава ППСП):

- лиц, часто появляющихся у объектов, где хранятся, находятся в обращении материальные ценности, банковских учреждений, торговых предприятий, складов, баз и проявляющих интерес к состоянию окон, дверей, запоров, ограждений, режима работы и организации охраны;

- лиц, занимающихся бродяжничеством и попрошайничеством;

- целостность дверей, витрин и окон магазинов и других учреждений, где хранятся ценности;

- подозрительные шумы, появление огня или дыма в зданиях и на объектах.

Главная задача ППСП в сфере сохранности собственности - это лишение подозреваемого (подозреваемых) в совершении преступления и правонарушения имущественного характера, возможности продолжить противоправные действия и его (их) задержание, а также оказание помощи потерпевшим.

Подразделения по обеспечению безопасности дорожного движения при исполнении государственной функции по контролю и надзору за соблюдением участниками дорожного движения требований в области обеспечения безопасности дорожного движения реализуют следующие административные процедуры для выявления и пресечения преступлений и правонарушений применительно к сфере сохранности собственности (п.31 Приказа МВД России №185-2009г.[Ошибка! Источник ссылки не найден.]):

- проверка идентификационного номера, номера кузова, шасси, двигателя транспортного средства, документов, государственных регистрационных знаков, технического состояния транспортного средства; 
- задержание транспортного средства;

- осмотр транспортного средства и груза;

- досмотр транспортного средства;

- личный досмотр, досмотр вещей, находящихся при физическом лице;

- изъятие вещей и документов;

- арест вещей;

- изъятие вещей и документов;

- арест вещей.

При осуществлении контроля за дорожным движением принимаются меры к выявлению и задержанию транспортных средств, находящихся в розыске [Ошибка! Источник ссылки не найден.]; пресечению преступлений и нарушений общественного порядка и безопасности.

При выявлении транспортных средств, находящихся в розыске по ориентировкам или по оперативно-справочным учетам, лиц, находящихся в розыске или подозреваемых в совершении преступлений, соответствующая информация передается дежурному, дальнейшие действия осуществляются в соответствии с его указаниями.

При установлении в ходе осуществления действий, связанных с остановкой транспортного средства, признаков состава или события преступного деяния, принимаются меры к задержанию лиц, причастных к его совершению, соответствующая информация докладывается дежурному для принятия решения о вызове следственно-оперативной группы либо доставления задержанных в орган внутренних дел.

Наиболее часто деятельности сотрудников ДПС ГИБДД применяются следующие административные меры по выявлению похищенного имущества:

1. Осмотр транспортного средства и груза: основаниями для осмотра транспортного средства и груза, то есть визуального обследования транспортного средства и перевозимого груза, являются:

$\checkmark$ ориентировки, иная информация об их использовании в противоправных целях;

$\checkmark$ необходимость проведения сверки маркировочных обозначений транспортного средства с записями в регистрационных документах

$\checkmark$ наличие признаков несоответствия перевозимого груза данным, указанным в документах на перевозимый груз; 
О проведении осмотра транспортного средства и груза по основаниям, предусмотренным Ф3 «О полиции», сотрудник составляет акт осмотра транспортного средства и груза.

2. Досмотр транспортного средства: основаниями для досмотра транспортного средства, то есть обследования транспортного средства, проводимого без нарушения его конструктивной целостности, являются:

$\checkmark$ проверка обоснованного предположения о наличии в транспортном средстве оружия, боеприпасов, патронов к оружию, взрывчатых веществ, взрывных устройств, наркотических средств, психотропных веществ или их прекурсоров либо ядовитых или радиоактивных веществ $<$

$\checkmark$ проверка обоснованного предположения о наличии орудий совершения либо предметов административного правонарушения в транспортном средстве или следов административного правонарушения на транспортном средстве.

О досмотре транспортного средства в соответствии с положениями статьи КоАП РФ составляется протокол или делается соответствующая запись в протоколе об административном задержании.

В случае одновременного возникновения обстоятельств, требующих реагирования сотрудника, в приоритетном порядке осуществляются действия, направленные на сохранение жизни и здоровья граждан, объектов государственной охраны, предупреждение дорожно-транспортных происшествий.

Подразделения по исполнению административного законодательства, в том числе подразделения по содержанию лиц, арестованных в административном порядке, реализуют деятельность, направленную на организацию и выполнение подразделениями полиции задач по предупреждению и пресечению административных правонарушений, отнесенных законодательством к компетенции органов внутренних дел, а также обеспечению производства по делам об административных правонарушениях, исполнения административных наказаний [Ошибка! Источник ссылки не найден.].

Для реализации поставленных задач, указанные подразделения осуществляют следующие функции, направленные на:

$\checkmark$ выработку системного подхода к осуществлению подразделениями полиции административной практики в условиях неукоснительного 
соблюдения требований законодательства Российской Федерации об административных правонарушениях и нормативных правовых актов Министерства внутренних дел Российской Федерации в сфере его применения (п.15. Приказа МВД России №1156-2012г.);

$\checkmark$ оказание практической помощи подразделениям полиции при осуществлении производства по делам об административных правонарушениях, пресечении административных правонарушений, требующих проведения административного расследования, а также рассматриваемых в порядке арбитражного процессуального производства в установленных законодательством случаях (п.21. Приказа МВД России №1156-2012г.);

$\checkmark$ участие в формировании банков данных о лицах, в отношении которых осуществляется производство по делам об административных правонарушениях, и подготовке статистических отчетностей, содержащих сведения о деятельности органов внутренних дел по административной практике (п.24. Приказа МВД России №1156-2012г.).

Подразделения по делам несовершеннолетних, в том числе подразделения для временного содержания несовершеннолетних правонарушителей (далее ПДН), проводят индивидуальную профилактическую работу в отношении несовершеннолетних правонарушителей, а также выявляют лиц, вовлекающих несовершеннолетних в совершение преступления и (или) антиобщественных действий или совершающих в отношении несовершеннолетних другие противоправные деяния, а также родителей несовершеннолетних или иных их законных представителей и должностных лиц, не исполняющих или ненадлежащим образом исполняющих свои обязанности по воспитанию, обучению и (или) содержанию несовершеннолетних [Ошибка! Источник ссылки не найден.].

Основной метод административный деятельности территориальных ПДН в противодействии имущественным преступлениям и административным правонарушениям среди несовершеннолетних - это метод убеждения, связанный с проведением разъяснительной профилактической работы по месту обучения и жительства несовершеннолетних, а также метод принуждения, в виде пресечения наказуемых противоправных деяний в исследуемой области [Ошибка! Источник ссылки не найден., С.7-17.], и подготовка материалов на злостных несовершеннолетних правонарушителей для их изоляции от общества. 
Подразделения по охране дипломатических представительств и консульств иностранных государств реализуют основные задачи, связанные с сохранностью собственности [Ошибка! Источник ссылки не найден.]:

- обеспечением охраны и безопасности представительств и консульств с целью их защиты от несанкционированного проникновения, противоправных действий и иных преступных посягательств;

- охраной общественного порядка и обеспечение общественной безопасности, пресечение преступлений и административных правонарушений на территории, непосредственно прилегающей к представительствам и консульствам, в том числе во взаимодействии с другими подразделениями органов внутренних дел.

Реализация указанных задач данных подразделений в сфере обеспечения имущественной безопасности осуществляется посредством исполнения следующих функций:

$\checkmark$ обеспечивают неприкосновенность представительств и консульств, их защиту от противоправных посягательств, пресекают попытки совершения преступных, провокационных и иных действий, которые могут привести к осложнению межгосударственных отношений и другим нежелательным последствиям;

$\checkmark$ обеспечивают совместно с другими подразделениями органов внутренних дел охрану представительств и консульств в период подготовки и проведения протокольных мероприятий, а также других публичных мероприятий;

$\checkmark$ принимают, по согласованию с администрацией представительств и консульств, неотложные меры по обеспечению охраны и безопасности сотрудников представительств и консульств, членов их семей, а также помещений и имущества в случае чрезвычайных происшествий;

проводят анализ и оценку состояния охраны представительств и консульств, обеспечения правопорядка на территории, непосредственно прилегающей к представительствам и консульствам. Ведут учет результатов своей деятельности, подготавливают соответствующие информационные и отчетные документы, изучают и внедряют передовые формы и методы организации работы; 
вносят в подразделения организации охраны общественного порядка и взаимодействия с органами исполнительной власти субъектов Российской Федерации и органами местного самоуправления территориальных органов МВД России на региональном уровне или отдел (отделение, группу) охраны общественного порядка территориальных органов МВД России на районном уровне соответственно предложения по организации охраны и обеспечению безопасности представительств и консульств, а также по взаимодействию с другими правоохранительными органами.

участвуют в пределах своей компетенции в подготовке проектов нормативных правовых актов по вопросам охраны и обеспечения безопасности представительств и консульств;

$\checkmark$ участвуют в установленном порядке в подготовке и реализации федеральных, региональных и иных программ и мероприятий по охране и обеспечению безопасности представительств и консульств;

$\checkmark$ осуществлют иные полномочия, предусмотренные законодательством Российской Федерации и нормативными правовыми актами МВД России.

В России сохраняется тенденция, когда число преступных посягательств на чужое имущество (в частности кражи, грабежи и разбои) составляет больше половины от всех регистрируемых преступлений и их доля постоянно растет. Кроме того, по различным причинам собственники имущества не всегда сообщают в правоохранительные органы о случаях посягательств на принадлежащее им имущество. Обеспечение имущественной безопасности предполагает нейтрализацию угроз правового режима имущества по его владению, пользованию и распоряжению.

Государство в лице сотрудников подразделений полиции гарантирует защиту от противоправных посягательств в отношении имущества, находящегося в собственности или на ином правовом основании у граждан и организаций. 
1. Приказ МВД РФ от 17.02.1994 № 58 (ред. от 12.09.2000) «О мерах по усилению борьбы с преступными посягательствами на автомототранспортные средства» (вместе с «Инструкцией по розыску автомототранспортных средств»).

2. Приказ МВД России от 29.01.2008 № 80 (ред. от 12.02.2015) «Вопросы организации деятельности строевых подразделений патрульно-постовой службы полиции» (вместе с «Уставом патрульно-постовой службы полиции».

3. Приказ МВД России от 26.05.2008 № 460 (ред. от 31.10.2013) «Об утверждении Типового положения о подразделениях по охране дипломатических представительств и консульств иностранных государств территориальных органов Министерства внутренних дел Российской Федерации».

4. Приказ МВД России от 02.03.2009 № 185 (ред. от 22.12.2014) «Об утверждении Административного регламента Министерства внутренних дел Российской Федерации исполнения государственной функции по контролю и надзору за соблюдением участниками дорожного движения требований в области обеспечения безопасности дорожного движения».

5. Приказ МВД России от 29.12.2012 № 1156 «Об утверждении Типовых положений о подразделениях организации применения административного законодательства и подразделениях по исполнению административного законодательства».

6. Приказ МВД России от 31.12.2012 № 1166 (ред. от 08.09.2016) «Вопросы организации деятельности участковых уполномоченных полиции».

7. Приказ МВД России от 15.10.2013 № 845 «Об утверждении Инструкции по организации деятельности подразделений по делам несовершеннолетних органов внутренних дел Российской Федерации».

8. Бецков А.В., Елагин А.Г., Николаев А.Г. Административно-правовые средства организации деятельности подразделений полиции специального назначения, при обеспечении общественного порядка: учебное пособие. - Издание второе, доработанное. - М.: ТЕИС, 2015. - 112 с.

9. Гендеев Э. Н., Николаев А. Г. Административно-правовые отношения, возникающие в деятельности подразделений по делам несовершеннолетний органов внутренних дел на объектах транспортной инфраструктуры // Электронный научный журнал «Транспортное право и безопасность» №2(2) 2016. С.7-17.

10. Шевцов А.В, Семенистый А.В., Ускова А.С., Николаев А.Г., Коновалов А.А. Полномочия сотрудников органов внутренних дел при осуществлении административно - юрисдикционного производства: учебное пособие. - М.: Академия управления МВД России, 2016. - 192с. 